\title{
SIMBOLISME KEPEMIMPINAN TRANSFORMASIONAL DALAM OPTIMALISASI DIRI PUSTAKAWAN
}

\author{
Henny Surya Akbar Purna Putra*
}

Abstract: Today the library is a dynamic organization, going inside to fulfill the dynamism of this matter which is crucial thing that is element of leadership. Nowadays it has been discovered that different types of leadership can be the successor to which a leader can apply that type, so that when that type of leadership becomes the leader's principle, it will create a certain symbolism. There is a charismatic type of other types of leadership, the transformational leadership style. This leadership style is based on the follower's satisfaction in addition to the goal achievement orientation, so this style is more supportive of the followers (librarians) to reach their orientation. Therefore, this research as a search for the symbolism that appears in its implications for self-autonomy librarians. Analysis used in this research, that is by using literature study. Researchers reviewed the literature with the primary literature is the literature of Bass \& Riggio entitled "Transformational Leadership".

Keywords: Leadership style, Transformational Leadership, Management

\section{PENDAHULUAN}

Perpustakaan dewasa ini mempunyai peran yang penting bagi perkembangan peradaban manusia, sebab perpustakaan berperan sebagai fasilitator dalam menunjang intelektualitas manusia. Perpustakaan sebagai fasilitator mengingat bahwa peranannya dalam menyediakan, mengelola, penelitian, informasi, dan rekreasi (P3IR) ${ }^{1}$, selain itu juga perpustakaan bersifat dinamis dalam menyediakan koleksi keilmuan, oleh karenanya koleksi-koleksi dalam berbagai

\footnotetext{
*Mahasiswa Universitas Islam Negeri Sunan Kalijaga. Email: putra.akademisi@gmail.com

1 ___ “Undang-Undang Republik Indonesia Nomor 43 Tahun 2007 tentang Perpustakaan", Bab I Pasal 1.
} 
bentuk pun disediakan oleh perpustakaan. Sejalan dengan pandangan di atas Sulistyo-Basuki (1990) yang mengejawantahkan perpustakaan berdasarkan terminologi, berpendapat bahwa perpustakaan berasal dari kata liber = libri yang artinya adalah "pustaka" atau kitab, sehingga perpustakaan (library) adalah sebuah ruangan, bagian sebuah gedung, yang digunakan untuk menyimpan buku dan terbitan lainnya yang disusun menurut tata susunan tertentu untuk digunakan pembaca bukan untuk dijual. ${ }^{2}$ Sehingga perpustakaan sebagai penghimpun koleksi-koleksi khasanah keilmuan, perpustakaan juga melayankan koleksi tersebut bagi pemustaka tanpa dipungut biaya.

Pluralisme masyarakat dewasa ini menjadi aspek fundamental dalam orientasi koleksi-koleksi yang tepat guna bagi pemustakanya. Oleh karena itu perpustakaan dikelompokkan menjadi lima, antara lain: perpustakaan Nasional, perpustakaan umum, perpustaakan perguruan tinggi, perpustakaan sekolah/ madrasah, dan perpustakaan khusus. ${ }^{3}$ Pengelompokkan perpustakaan di atas agar semata-mata perpustakaan secara efektif sebagai fasilitator dalam mendukung sarana keilmuan bagi ruang lingkup perpustakaan. Selain itu terdapat juga perpustakaan berbasis komunitas yang tidak kalah pentingnya sebagai fasilitator keilmuan. Seperti salah satunya adalah taman baca masyarakat (TBM) yang dikelola dalam ruang lingkup masyarakat kecil, akan tetapi peranannya tidak dapat dipandang sebelah mata ketika sasaran TBM adalah pembangunan intelektualitas dan kreativitas anak-anak sebagai generasi penerus bangsa. Kedua organisasi di atas dapat bertahan dan eksis hingga saat ini tidak terlepas dengan peran seorang pemimpin yang menerapkan gaya-gaya kepemimpinan tertentu, agar semata-mata orientasi organisasi dapat tercapai dengan baik. Pendapat di atas sejalan dengan Hartono, berpendapat bahwa dewasa ini masih banyak perpustakaan yang menggunakan cara administrasi perkantoran biasa atau manajemen tradisional. Cara ini masih memiliki kekurangan dalam mengembangkan beberapa bidang, seperti contoh: bidang layanan yang selalu monoton dan kurang

\footnotetext{
${ }^{2}$ Hartono, “Manajemen Perpustakaan Sekolah”, (Yogyakarta: Ar-Ruzz Media, 2016), 26.
}

, Undang-Undang Republik Indonesia....20. 
menantang dalam kegiatan peminjaman dan pengembalian buku, disebabkan oleh masuknya pimpinan ke dalam bidang khusus sehingga tanggung jawab pada tingkat bawahan berkurang. ${ }^{4}$

Perpustakaan adalah sebuah unit kerja yang melayani masyarakat pemakainya, ${ }^{5}$ oleh sebab itu pengelolaan perpustakaan menjadi hal yang krusial sebagai catatan pemimpin. Pemimpin mempunyai peranan kunci dalam kesuksesan perpustakaan, oleh karena itu perlunya tinjauan tentang berbagai kepemimpinan yang hendaknya diimplementasikan di perpustakaan. Dewasa ini terdapat beberapa tipe kepemimpinan, dalam Marlina mengelompokkan terdapat lima tipe kepemimpinan, yaitu: otokratis, bebas (laisze fair), demokratis, dan karismatik, militeristik. ${ }^{6}$ Pada setiap tipe-tipe kepemimpinan di atas mempunyai simbolisme yang menjadi ciri khas disetiap tipe kepemimpinan. Pada posisional ini, pengikut mempunyai arti adalah "pegawai" dalam Kamus Berbahasa Indonesia (KBBI) pegawai adalah sekelompok orang yang bekerja membantu seorang direktur, ketua, dan sebagainya mengelola sesuatu. ${ }^{7}$ Sehingga pengikut di sini dapat diintepretasikan adalah sekolompok orang yang bekerja sama dengan pemimpin dalam mencapai orientasi organisasi. Pengikut mempunyai hak dalam menilai tipe dan gaya kepemimpinan dalam lingkup organisasinya, sebab dengan menilai simbolisme yang muncul disetiap gaya kepemimpinan, seorang pengikut akan mampu beradabtasi atau bersifat menolak terhadap gaya kepemimpinan atasan. Simbolisme di atas adalah langkah awal dalam mengintepretasikan gaya kepemimpinan.

Pada dasarnya setiap kepemimpinan (leadership) terdapat kelebihan dan kekurangannya masing-masing, sehingga tidak menutup kemungkinan akan menimbulkan gejolak dan bahkan menimbulkan permasalahan dalam organisasi. Oleh karena itu penelitian tentang "simbolisme kepemimpinan transformasional dalam optimalisasi diri pustakawan" ini mempunyai keterkaitan erat

\footnotetext{
${ }^{4}$ Hartono, Manajemen Perpustakaan Sekolah....44.

${ }^{5}$ Ibid., 45.

${ }^{6}$ Hadari Nawawi \& M. Martini Hadari. Kepemimpinan yang Efektif. (Yogyakarta: Gajah Mada Univessity Press, 1995), 94.

${ }^{7}$ Kementerian Pendidikan dan Kebudayaan Republik Indonesia, Kamus Berbahasa Indonesia, diakses pada 6 Desember 2017 di: https://kbbi.kemdikbud.go.id/entri/pegawai
} 
dengan pengorganisasian perpustakaan. Penelitian ini sebagai landasan dalam penggalian simbolisme yang muncul pada gaya kepemimpinan transformasional dan meninjau gaya kepemimpinan transformasional ini memotivasi pengikut, sebagaimana dewasa ini pengikut mempunyai cara pandang yang berbeda-beda, mempunyai intensitas diri masing-masing, mempunyai kelebihan dan kekurangan masing-masing, sehingga gaya kepemimpinan transformasional ini dapat sebagai solusi dalam mencari jalan tengah terhadap kekompleksan pengikut tersebut.

\section{Tipe Kepemimpinan}

Ditinjau berdasarkan kesejarahannya, embrio tentang konsep kepemimpinan sebenarnya telah ada sejak awal peradaban manusia. Manusia dikaruniai kemampuan untuk belajar, dengan kemampuan ini manusia berusaha untuk tidak mengulangi kesalahan-kesalahan yang mereka buat pada masa lalu. Ketika manusia mulai belajar untuk tidak mengulangi masa lalu tersebut, manusia sadar bahwa mereka tidak dapat hidup seorang diri, melainkan membutuhkan manusia lain untuk membantu mereka dalam proses belajar. Awal mula di atas sebagai embrio bahwa manusia terikat dalam kelompok sosial, ketika manusia telah tergabung dalam kelompok sosial, maka tidak dapat terlepas pula dengan peran seorang pemimpin yang mengarahkan kelompok sosial tersebut ke arah yang mempunyai visi dan misi.

Pandangan Islam, konsep kepemimpinan telah ada secara etomologis, kata khalifah didasari pada huruf $k h \bar{a}^{\prime}$, lām, dan $f \bar{a}^{\prime}$ yang mempunyai arti, yaitu: mengganti, belakang, dan perubahan. Makna di atas, mengandung tiga arti, yaitu: kata kerja khalafa, yaklhufu, khalīfah dapat mempunyai arti bahwa khalifah adalah pengganti kedudukan Nabi sebagai pemimpin; khalifah adalah pemimpin di belakang (sesudah) Nabi; khalifah adalah pemimpin orang yang mampu mengadakan perubahan untuk lebih maju dan menyejahterakan orang yang dipimpinnya. ${ }^{8}$ Tafsir di atas telah menjelaskan bahwa leadership adalah perihal yang penting bagi

\footnotetext{
${ }^{8}$ Surahman Amin \& Ferry Muhammadsyah Siregar, "Pemimpin dan Kepemimpinan dalam AL-Quran", (Jurnal Studi AL-Quran, Vol. 1, No. 1, 2015, 2740), 29.
} 
kesejahteraan pengikutnya, sehingga dalam konteks penulisan ini sosok leadership sebagai core bagi kesejahteraan secara internal atau pun eksternal organisasi. Di lain sisi, perkembangan keilmuan terkhusus ilmu manajemen telah banyak mengejawantahkan definisidefinisi tentang kepemimpinan (leadership), sehingga definisi-definisi tersebut memperkuat cakupan-cakupan sebagai seorang pemimpin. Paradigma tentang kepemimpinan secara tampak mempunyai dua dimensi, antara dimensi motivasional dan dimensi praktis, seperti yang tertera dalam beberapa definisi sebagai berikut.

Kepemimpinan (leadership) adalah suatu proses mempengaruhi antar pribadi yang dijalankan dalam situasi tertentu melalui komunikasi dan diarahkan pada beberapa tujuan tertentu. ${ }^{9}$ Sebuah proses pengaruh sosial yang sengaja dijalankan oleh seseorang terhadap orang lain untuk menstrukturkan aktifitas dan hubungan kelompok (organisasional). ${ }^{10}$ Kepemimpinan adalah pengaruh sedikit demi sedikit diatas kepatuhan mekanis terhadap pengarahan rutin organisasi. ${ }^{11}$ Proses mempengaruhi aktifitas sebuah kelompok yang diorganisasi kearah pencapaian tujuan. ${ }^{12}$ Paradigma di atas tampak jelas bahwa kepemimpinan mempunyai dua dimensi yang dimana otoritas sebagai seorang pemimpin hendaknya mampu memotivasi dan mengarahkan secara praktis pengikut dalam pencapian tujuantujuan organisasi.

Tipe kepemimpinan dengan mengacu Marlina, mengelompokkan menjadi lima tipe kepemimpinan, antara lain: kepemimpinan otoriter, kepemimpinan bebas (leissez fair), kepemimpinan demokratis, kepemimpinan kharismatik, dan kepemimpinan militeristik. Tipe-tipe kepemimpinan di atas akan dijelaskan pada tabel berikut.

\footnotetext{
${ }^{9}$ Tannenbaum, R., Weschler, I. R., \& Massarik, F. Leadership and Organization. (New York: McGraw-Hill, 1961), 24.

${ }^{10}$ Yukl, G.A. Leadership in Organizations, 3rd ed., (Prentice-Hall, Englewood Cliffs, NJ, 1994), 2.

${ }^{11}$ Katz, Daniel \& Kahn, Robert L. The Social Psychology Of Organizations. (Canada: John Wiley And Sons, 1978), 528.

${ }^{12}$ Yukl, G.A. (1994), Leadership in Organizations...2.
} 
Tabel 1. Tipe dan Sikap Kepemimpinan dalam Marlina ${ }^{13}$

\begin{tabular}{|c|c|c|}
\hline No. & $\begin{array}{c}\text { Tipe } \\
\text { Kepemimpinan }\end{array}$ & Sikap Kepemimpinan \\
\hline 1. & Otoriter & $\begin{array}{l}\text { Menganggap organisasi sebagai milik pribadi; } \\
\text { Mengindentikan tujuan pribadi dengan } \\
\text { tujuan organisasi; Menganggap bawahan } \\
\text { sebagai alat semata-mata; Tidak mau } \\
\text { menerima kritik, saran dan pendapat; } \\
\text { Tergantung pada kekuasaan formilnya; } \\
\text { Tindakan pengerakannya sering } \\
\text { mempergunakan approach mengandung } \\
\text { unsur paksaan dan bersifat menghukum }{ }^{14}\end{array}$ \\
\hline 2. & Bebas & $\begin{array}{l}\text { Pendelegasian wewenang terjadi secara } \\
\text { ekstensif; Pengambilan keputusan diserahkan } \\
\text { kepada para pejabat yang lebih rendah dan } \\
\text { para petugas operasional; Statusquo } \\
\text { organisasional tidak terganggu; Penumbuhan } \\
\text { dan pengembangan kemampuan berfikir dan } \\
\text { bertindak inovatif dan kreatif diserahkan } \\
\text { kepada para anggota; Intervensi pimpinan } \\
\text { dalam perjalanan organisasi berada pada } \\
\text { tingkat yang minimum ketika prestasi kerja } \\
\text { anggota memadahi. }\end{array}$ \\
\hline 3. & Demokratis & $\begin{array}{l}\text { Kemampuan pemimpin mengintegrasikan } \\
\text { organisasi pada peranan dan porsi yang } \\
\text { tepat; Mempunyai persepsi yang holistik; } \\
\text { Menggunakan pendekatan integralistik } \\
\text { organisasi secara keseluruhan; Menjunjung } \\
\text { tinggi harkat dan martabat bawahan; } \\
\text { Bawahan berpartisipasi dalam pengambilan } \\
\text { keputusan, Terbuka terhadap ide, } \\
\text { pandangan, dan saran dari bawahannya; } \\
\text { Teladan; Bersifat rasional dan obyektif; }\end{array}$ \\
\hline
\end{tabular}

${ }^{13}$ Hadari Nawawi \& M. Martini Hadari. Kepemimpinan yang Efektif...94.

${ }^{14}$ Nanang, Landasan Manajemen Pendidikan, (Bandung: Remaja Rosda Karya, 2004), 169.

${ }^{15}$ Sondang P. Siagian (1994), 39-40 


\begin{tabular}{|l|l|l|}
\hline & & $\begin{array}{l}\text { Memelihara kondisi kerja yang kondusif, } \\
\text { inovatif dan kreatif. }\end{array}$ \\
\hline 4. & Kharismatik & $\begin{array}{l}\text { Memberi contoh; Menunjukkan tekad; } \\
\text { Menampilkan bakat luar biasa; Mengambil } \\
\text { resiko; Menciptakan rasa pemberdayaan } \\
\text { bawahan; Menunjukkan dedikasi; dan } \\
\text { Menggugah rasa misi bersama }\end{array}$ \\
\hline Militeristik & $\begin{array}{l}\text { Bawahan lebih sering mempergunakan } \\
\text { system perintah; Bawahan senang } \\
\text { bergantung kepadapangkat dan jabatannya; } \\
\text { Senang kepada formalitas yang berlebih- } \\
\text { lebihan; Menuntut disiplin yang tinggi dan } \\
\text { kaku dari bawahan; Sukar menerima kritikan } \\
\text { dari bawahannya; Menggemari upacara- } \\
\text { upacara untuk berbagai keadaan. }\end{array}$ \\
\hline
\end{tabular}

\section{Manajemen Perpustakaan}

Perpustakaan sebagai tempat berkumpulnya sumberdaya manusia yang satu visi dan misi, mempunyai cakupan kerja secara fundamental. Cakupan kerja ini terdapat pada unsur manajemen suatu perpustakaan, sebab unsur manajemen ini sebagai landasan dalam pijakan ke arah yang lebih dinamis. Hartono berpendapat bahwa manajemen perpustakaan mencangkup lima unsur, yaitu: perencanaan (planning), pengorganisasian (organizing), pengelolaan tenaga kerja (staffing), pemotivasian (motivating), dan pengontrolan (controling). ${ }^{17}$

1. Perencanaan (Planning)

Davies \& Filley (1971) menyatakan bahwa perencanaan adalah pekerjaan menentukan dan merinci sasaran, kebijakan, program, hubungan organisatoris, prosedur, dan anggaran. Sisk (1977) menyatakan bahwa perncanaan adalah penganalisisan informasi yang relevan dari sekarang dan masa lampau serta melakukan perkiraan kemungkinan perkembangan pada masa yang akan datang dalam menentukan tindakan yang dilakukan untuk

16 John B. Miner, Organizational Behaviour I: essential theories of motivation and leadership. (London: M.E Sharpe, 2005),.

${ }^{17}$ Hartono, Manajemen perpustakaan sekolah...46. 
mencapai sasaran organisasi. Sedangkan Hartono menyatakan bahwa perencanaan adalah kegiatan dalam menyusun sasaran dan sumber daya yang diperlukan dalam kurun waktu tertentu untuk masa yang akan datang sesuai dengan tugas dan fungsi yang ditetapkan untuk mencapai tujuan perpusdokinfo. Sehingga dapat diintepretasikan bahwa kegiatan perencanaan ini lebih pada proses belajar, yang dimana memproyeksikan hal-hal sekarang dan masa lampau untuk memprediksikan masa depan. Pendapat di atas sejalan dengan perpusdokinfo yang menyatakan beberapa fungsi perencanaan, yaitu: pedoman untuk mengambil keputusan di masa depan; sebagai prosedur, metode, dan proses tata kerja dalam menyelesaikan pekerjaan; program kerja dan jadwal pelaksanaan kegiatan secara berurutan; panduan anggaran yang dibutuhkan; jaringan; diagram desain, market, pola; dan model yang dijadikan pedoman penyelesaian pekerjaan. ${ }^{18}$

2. Pengorganisasian (Organizing)

Pengorganisasian adalah pendelegasian wewenang pimpinan, pendelegasian wewenang ini mempunyai fungsi sebagai pendistribusian tugas kepada pengikut. Pengorganisasian dalam lingkup organisasi perpustakaan ini mencangkup lima hal penting, sebagai berikut.

a. Pemilihan pengikut, akan tetapi pemilihan pengikut ini lebih mendalam dengan menggunakan prinsip the right man on the right place. Oleh karena itu diperlukannya penyaringan yang ketat terhadap sumber daya manusia (SDM) dalam instansi, agar kompentensi pengikut sesuai dengan bidang yang akan dinaunginya. Terdapat beberapa tahapan dalam pemilihan ini, yaitu: 1) membuat analisis dan perhitungan SDM yang diperlukan, 2) menganalisis kondisi dan mutu, 3) melakukan pengembangan tenaga baru yang dibutuhkan, 4) menyiapkan SDM yang akan dipakai melalui pelatihan sesuai dengan kebutuhan, dan 5) menyiapkan surat penugasan tentang penempatan staf.

b. Penstrukturan, terdapat dua kegiatan utama pada penstrukturan yang mencakup dua hal: 1) Pendistribusian 
tugas, kegiatan ini mempunyai maksud agar progam kerja dapat dilaksanakan oleh semua pengikut secara sesuai, dan efektif. Sehingga pengelompokkan ini diperlukannya pertimbangan kriteria-kriteria pengikut, seperti: pengetahuan, keterampilan, alokasi waktu, dan SDM yang tersedia. 2) Pembentukan struktur, dimaksudkan sebagai struktur organisasi dalam instansi, struktur ini mempunyai fungsi agar jelasnya posisional disetiap divisi.

c. Fungsionalisasi, adalah penentuan tugas dan fungsi setiap SDM dan unit satuan kerja, akan tetapi tahapan ini ditinjau berdasarkan fungsinya.

d. Kepela unit kerja, menyangkut kepala unit yang bertanggun jawab pada pengelolaan administrasi, kepegawaian, gedung, dan perlengkapan.

e. Tanggung jawab manajemen perpustakaan, ini adalah peran sebagai seorang pemimpin yang bertanggung jawab terhadap instansi. Tanggung jawab ini meliputi: (a) perumusan tujuan dan sasaran rencana kerja yang harus dicapai oleh perpustakaan secara keseluruhan (jangka panjang dan jangka pendek), (b) menyusun program, kegiatan, dan mengatur mekanisme pelaksanaan kerja untuk mencapai tujuan dan sasaran, (c) menyediakan tenaga, anggaran, perlengkapan, dan sarana-prasarana, (d) menyusun Laporan Pertanggung Jawaban (LPG) dari seluruh pelaksanaan program, tenaga, dan sumber daya lainnya.

\section{Simbolisme Gaya Kepemimpinan Transformasional}

Simbolisme dalam KBBI berasal dari kata simbol= lambang, isyarat, lalu kemudian terdapat penambahan kata "simbol-isme" yang menjadi "simbolisme", sehinga mempunyai arti penggunaan simbol untuk mengekspresikan ide-ide. ${ }^{19}$ Terminologi di atas dapat diintepretasikan bahwa simbolisme adalah penggunaan simbol atau pun isyarat tertentu dalam mengekspresikan ide. Simbolisme ini mempunyai implikasi terhadap simbol atau isyarat yang muncul dari gaya kepemimpinan seorang pemimpin, sehingga pada posisi ini

${ }^{19}$ Kamus Berbahasa Indoensia (KBBI), diakses pada 19 Januari 2018 di https://kbbi.kemdikbud.go.id/entri/simbolisme 
pengikut dapat menangkap dan mengintepretasikan simbol yang muncul dari seorang pemimpin. Pemimpin secara fundamental yang mempunyai kapabilitas dalam hal mempengaruhi pengikutnya untuk mencapai target organisasi, oleh karena itu seorang pemimpin juga telah memahami manajemen dalam menjalanakan tugasnya.

Mengacu pada Avolio \& Bass (2002) dalam bukunya "Developing Potencial Across a Full Range Of Leadership", para ahli di atas bertolak pada dua gaya kepemimpinan dalam kasus transaksional dan transformasional. Kedua gaya kepemimpinan ini mempunyai tujuan yang sama yaitu dukungan secara motivasional, akan tetapi metode yang digunakan oleh kedua gaya ini mempunyai perbedaan secara fundamental. Berikut akan dijelaskan pada tabel di bawah ini.

Tabel 2. Perbedaan Gaya Kepemimpinan Transaksional dengan Transformasional

\begin{tabular}{|c|l|l|}
\hline No. & \multicolumn{1}{|c|}{$\begin{array}{c}\text { Gaya } \\
\text { Kepemimpinan }\end{array}$} & \multicolumn{1}{c|}{ Ciri-Ciri Kepemimpinan } \\
\hline 1. & Transaksional & $\begin{array}{l}\text { Contingent Reward (CR); Management } \\
\text { Beyond Exception (MBE); Laissez Faire (LF). }\end{array}$ \\
\hline 2. & Transformasional & $\begin{array}{l}\text { Idealized Leadership (IL); Inspirational } \\
\text { Motivation (IM); Intellectual Stimultaion } \\
\text { (IS), Individualized Consideration (IC). }\end{array}$ \\
\hline
\end{tabular}

Tabel 2. di atas, tampak beberapa perbedaan antara ciri-ciri kepemimpinan tranksaksional dengan transformasional. Ciri-ciri kepemimpinan pada transaksional terdapat tiga unsur, yaitu: contingent reward (CR), management by exception (MBE), dan laissez faire (LF).

1. Contingen Reward (CR) adalah sebuah metode dimana seorang pemimpin memberikan hadiah (reward) untuk memotivasi pengikut yang mempunyai kinerja tinggi.

2. Management By Exception (MBE) adalah sikap pemantauan dan pengambilan tindakan terhadap pengikut. MBE dibagi menjadi dua, yaitu: MBE (Aktif) dan MBE (Pasif). MBE Aktif pemimpin secara aktif memantau penyimpangan dan kesalahan yang dialami oleh pengikut, hal ini diperlukan untuk pemimpin mengambil tindakan yang korektif. Sebaliknya, pada MBE (Pasif) pemimpin 
menunggu laporan atau keluhan dari pengikut untuk mengambil tindakan yang korektif.

3. Laissez Faire (LF) adalah gaya kepemimpinan yang bebas, sehingga pengikut secara mandiri dalam melakukan beban kerja masingmasing. Sehingga dapat diintepretasikan poin penting dalam gaya kepemimpinan transaksional ini adadalah pemimpin memotivasi pengikut dengan menggunakan metode imbalan dalam menilai kinerja pengikut. ${ }^{20}$

Terdapat perbedaan secara fundamental metode yang diimplementasikan pada gaya kepemimpinan transformasional, gaya ini mengaplikasikan empat metode dalam memotivasi pengikut agar mengoptimalkan, yaitu: Idealized Leadership (IL); Inspirational Motivation (IM); Intellectual Stimultaion (IS), Individualized Consideration (IC).

1. Idealized Leadership (IL) adalah sebuah pengaruh yang diidealisasikan yang dalandaskan pada visi dan tujuan. Pemimpin mampu memenangkan kepercayaan dan respek dari para pengikut mereka, dengan menunjukkan kepada pengikutnya bahwa mereka dapat mencapai lebih daripada yang mereka percayai sebagai mungkin. $^{21}$

2. Inpirational Motivation (IM), adalah gaya kepemimpinan dengan memotivasi pengikut dengan membangkitkan antusiasme, memberi contoh, dan partisipatif untuk membantu kesulitan pengikut. $^{22}$

3. Intellectual Stimulation (IS), adalah gaya inovatif dari seorang pemimpin dalam mengerjakan segala sesuatu. ${ }^{23}$

4. Individualized Consideration (IC), adalah gaya kepemimpinan yang memperhatikan kebutuhan dan potensi-potensi yang dimiliki setiap pengikut. ${ }^{24}$

Sehingga dapat diintepretasikan bahwa pemimpin memotivasi pengikut dengan bertindak sebagai figur panutan, selain itu pemimpin mempunyai pemahaman yang mendalam terhadap

${ }^{20}$ Bruce J. Avolio \& Bernard M. Bass, Developing Potential Across a Full Range Of Leadership". (London: Lawrence Elbrium Associates Publisher, 2002), 3.

${ }^{22}$ Ibid
${ }^{23}$ Ibid
${ }^{24}$ Ibid 
pengikutnya. Hal ini berguna sebagai celah dimana seorang pemimpin dapat memberikan koreksi terhadap pengikut, agar dapat mengoptimalkan kinerja sesuai dengan kapabilitas mereka.

\section{Prinsip Gaya kepemimpinan Transformasional}

Pemimpin yang mengimplementasikan gaya kepemimpinan transformasional memiliki empat prinsip yang hendaknya dipegang seorang pemimpin, yaitu : Komitmen, Heroik, Kompetensi, dan Multi kecerdasan, sebagai berikut:

1. Komitmen

Hal krusial yang menjadi kekuatan dari sosok pemimpin transformasional adalah komitmen, komitmen yang ditunjukkan oleh seorang pemimpin secara emosional dapat menginspirasi dan meningkatkan kepercayaan diri pengikut dalam membangkitkan integritas kinerjanya. Sejalan dengan pendapat di atas Bass \& Riggio berpendapat bahwa pemimpin menggunakan inspirational motivation untuk menggugah komitmen pengikut dalam capaian tujuan. Inspirasi seorang pemimpin ini timbul di benak pengikut, ketika pengikut mempertimbangankan nilai moral yang terlibat dalam tugas mereka sebagai anggota unit, organisasi, dan profesi mereka. ${ }^{25}$ Pemimpin transformasional ini membawa komitmenya tidak dengan cara yang koersif, sehingga pengikut tidak merasa tertekan dan terbebani dengan komitmen yang pemimpin pegang. Gaya kepemimpinan transformasional mempunyai sifat yang memegang erat harga diri (self-esteem) seorang pengikut, hal ini akan berdampak pada terjaganya konsistensi konsep diri pengikut. $^{26}$

2. Heroik

Pemimpin transformasional mempunyai sifat heroik dalam gaya kepemimpinannya, sifat ini adalah cara berkorban untuk pengikut. Conger \& Kanungo (1998); House \& Shamir (1993) berpendapat bahwa pemimpin dapat mengorbankan diri dengan mengambil proporsional beban kerja yang lebih besar dengan mendahului perangkap keuasaannya. ${ }^{27}$ Sehingga sifat heroik ini semata-mata

${ }^{25}$ Bernard M. Bass \& Ronald E. Riggio, Transformasional Leadership. (London: Lawrence Erlbaum Associates Publishers, 2006), 36.

${ }^{26} \mathrm{Ibid}, 41$.

${ }^{27}$ Ibid, 44. 
untuk kepercayaan pengikut, Choi \& Mai-Dalton (1999) berpendapat bahwa beberapa gaya kepemimpinan transformasional yang mampu mengobankan dirinya dicontohkan oleh Gandhi, Lee Chrysler Lacoccam, dan Steve Jobs yang memutuskan untuk bekerja seharga $\$ 1$ per tahun. ${ }^{28}$

3. Kompetensi

Kepemimpinan yang transformasional dapat dimiliki seseorang bukan karena secara lahiriah telah dikaruniai sebagai pemimpin transformasional, melainkan kompetensi ini dapat dipelajari dengan mengasah kemampuan interpersonalnya. Conger \& Benjamin (1999) menyatakan terdapat lima kompetensi yang perlu diperhatikan, yaitu:

a) Critical evaluation and problem detection, kemampuan untuk evaluasi kritis dan deteksi masalah adalah kemampuan secara kritis dalam mengevaluasi gejala-gejala dan permasalahan yang timbul dalam organisasi, sehingga penyeleseian masalah dapat segera teratasi.

b) Envisioning, kemampuan untuk membayangkan ini berfungsi sebagai prediksi hal-hal yang kemungkinan muncul ketika menghadapi perubahan dimasa depan.

c) The communication skill for conveying a vision, adalah suatu kemampuan dalam menyampaikan visi secara menarik terhadap pengikut, kemampuan ini dapat dipelajari dengan menggunakan prinsip-prinsip retorika. Selain retorika yang dapat menginspirasi pengikut, kinerja seorang pemimpin juga mempunyai pengaruh yang signifikan.

d) Impression management, adalah kemampuan untuk menampilkan kharisma yang positif bagi pengikut. Kemampuan ini dapat ditampilkan berdasarkan perilkau yang dapat diteladani, percaya diri, bahasa tubuh dan kemampuan verbal.

e) How to when the empower followers, adalah tentang waktu yang tepat dalam memberdayakan pengikut. Peran pemimpin pada posisional ini, yaitu: pemimpin menyampaikan harapan-harapan kinerja yang tinggi, meningkatkan partisipasi dalam pengambilan keputusan, 
memberikan solusi terhadap kendala pengikut, menetapkan tujuan bersama, dan memberikan penghargaan yang sesuai oleh pengikut. ${ }^{29}$

4. Multi Kecerdasan

Seorang yang mempunyai otoritas sebagai pemimpin, hendaknya mempunyai multi kecerdasan. Kecerdasaan yang paling umum selama ini muncul adalah kecerdasan kognitif (IQ), akan tetapi berdasarkan perkembangannya terdapat kecerdasan lain yang hendaknya seorang pimpinan tekankan. Kecerdasan ini meliputi: kecerdasan sosial (interpersonal), kecerdasan emosional, dan kecerdasan praktis, sebagai berikut.

a) Cognitive Intelligence, kecerdasan kognitif diperlukan sebagai pemimpin transformasional, karena pemimpin adalah sosok panutan bagi pengikut. Kecerdasan berguna dalam membimbing dan memberikan solusi yang tepat bagi pengikut.

b) Social Intelligence, Thorndike (1920) kecerdasan sosial sebagai kemampuan untuk berpikir dan bertindak bijaksana dalam situasi sosial dan mengelola pengikut. Lebih lanjut Zaccaro (2002) berpendapat bahwa kecerdasan sosial terdiri dari perseptifan sosial, pengetahuan dan penalaran sosia, keterampilan mempengaruhi sosial, dan perilaku fleksibelitas.

c) Emotional Intelligence, kecerdasan emosional ini lebih pada kemampuan untuk berempati kepada pengikut. Kemampuan emosional ini sebagai proses membangkitkan dan mengelola emosi pengikut agar tetap konsisten terhadap orientasi kerja.

d) Practical Intelligence, Stenberg et.al. (2000) berpendapat bahwa kecerdasan praktis adalah pengetahuan tentang bagaimana cara menyelesaikan sesuatu. Secara konseptual kecerdasan praktis ini sebagai cara merespons kendalakendala teknis yang dialami pengikut. 


\section{PENUTUP}

Berdasarkan hasil pembahasan di atas dapat diambil kesimpulan bahwa simbolisme gaya kepemimpinan transformasional dapat diketahui dengan pemahaman tentang poin-poin penting dari prinsip gaya kepemimpinan transformasional. Gaya kepemimpinan transformasional ini menitik beratkan pada humanistik yang menjadikan gaya ini mempunyai kekuatan sosial yang tinggi, sehingga ketika interaksi ini terjalin dengan efektif maka pemimpin dapat secara bijak dalam mengelola, mengkoreksi, dan mengevaluasi kendala-kendala yang dialami olehpengikut. Kemampuan gaya kepemimpinan transformasional khususnya pada multi kecerdasan ini adalah sebuah kekuatan bagi pemimpin yang berkharisma, akan tetapi dengan kharisma tersebut gaya kepemimpinan transformasional ditransferkan terhadap pengikut dengan cara yang positif.

\section{Daftar Pustaka}

“Undang-Undang Republik Indonesia Nomor 43 Tahun 2007 tentang Perpustakaan”, Bab I Pasal 1, 2007.

, Kamus Berbahasa Indonesia (KBBI). Diakses pada 19 Januari 2018 di https://kbbi.kemdikbud.go.id/entri/simbolisme

Avolio, Bruce J. \& Bass, Bernard M., "Developing Potential Across a Full Range Of Leadership". London: Lawrence Elbrium Associates Publisher, 2002.

Nawawi, Hadari \& Hadari, M. Martini. Kepemimpinan yang Efektif. Yogyakarta: Gajah Mada University Press, 1995.

Hartono, "Manajemen Perpustakaan Sekolah". Yogyakarta: Ar-Ruzz Media, 2016.

Katz, Daniel \& Kahn, Robert L, "The Social Psychology Of Organizations". Canada: John Wiley And Sons.

Miner, John B, "Organizational Behaviour I: essential theories of motivation and leadership". London: M.E Sharpe, 2005.

Nanang, "Landasan Manajemen Pendidikan". Bandung: Remaja Rosda Karya, 2004.

Surahman Amin \& Ferry Muhammadsyah Siregar, "Pemimpin dan Kepemimpinan dalam AL-Quran", Jurnal Studi AL-Quran, Vol. 1, No. 1, 2015. 
Tannenbaum, R., Weschler, I. R., \& Massarik, F, "Leadership and Organization". New York: McGraw-Hill, 1961.

Yukl, G.A, "Leadership in Organizations, 3rd ed.". Prentice-Hall, Englewood Cliffs, NJ, 1994. 